\title{
Razlike u percepciji sestrinstva između studenata sestrinstva i zaposlenih medicinskih sestara
}

1 Snježana Čukljek

1 Martina Smrekar

1 Sanja Ledinski Fičko

2 Vesna Konjevoda

1 Zdravstveno veleučilište

2 KB Sveti Duh

\section{Sažetak}

"

Posljednjih se nekoliko godina, zbog sigurnosti radnog mjesta, sestrinstvo nalazi na listi poželjnih zanimanja u Hrvatskoj. Prilikom odabira profesije budući studenti dolaze s formiranim stavovima o sestrinstvu i cijenjenosti profesije, koji su tijekom studija podložni promjenama.

Cilj ove kvalitativne studije bio je utvrditi mišljenja studenata sestrinstva i zaposlenih medicinskih sestara o zadaćama i ulogama medicinskih sestara, vrijednostima koje se vežu uz sestrinstvo i o prepoznatljivosti sestara te mišljenja ispitanika o tome što pacijenti, liječnici i društvo misle o medicinskim sestrama.

Medicinske sestre i studenti navode da su uloge i zadaće medicinskih sestara briga za pacijente i zadovoljavanje osnovnih ljudskih potreba. Obje skupine ispitanika navode da su medicinske sestre prepoznatljive po uniformi te u vezi s vrijednostima u sestrinstvu najčešće navode pojmove: brižnost i humanost. Zaposlene medicinske sestre najvažnijima smatraju uvjete rada, dok studenti na prvom mjestu navode pacijente, a navode $\mathrm{i}$ važnost znanja i vještina. Zaposlene medicinske sestre i studenti slažu se da pacijenti uglavnom imaju pozitivna i podijeljena mišljenja o medicinskim sestrama. Uočena je razlika u odgovorima medicinskih sestara i studenta s obzirom na njihova mišljenja o tome što društvo i liječnici misle o medicinskim sestrama. Studenti, za razliku od zaposlenih medicinskih sestara, navode da smatraju da društvo i liječnici imaju pozitivnija mišljenja o sestrama. Dio studenata smatra da društvo ima stereotipna mišljenja o medicinskim sestrama.

Rezultati istraživanja ukazuju da na razvoj profesionalnog identiteta i percepcije o sestrinstvu značajan utjecaj imaju mediji, okolina i edukacija. Mišljenja studenata sestrinstva u znatnoj su mjeri usklađena s mišljenjima zaposlenih medicinskih sestara, što može ukazivati na lakše uklapanje na radno mjesto po završetku studija.

Ključne riječi: sestrinstvo, percepcija, profesionalni identitet

Datum primitka: 09.06.2015.

Datum prihvaćanja: 12.09.2015.

Adresa za dopisivanje:

Snježana Čukljek, prof.

Zdravstveno veleučilište

Mlinarska 38, Zagreb

Tel.: 0038514595911

E-pošta: snjezana.cukljek@zvu.hr 


\section{Uvod}

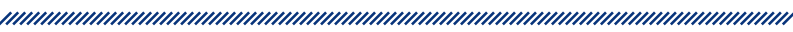

$\mathrm{Na}$ odabir profesije, tako i sestrinske profesije, značajno utječe slika koja se o njoj prezentira u javnosti. Na razvoj slike o profesiji s jedne strane utječu društvo i mediji, a s druge strane same medicinske sestre. Sigurnost radnog mjesta čini sestrinstvo poželjnim zanimanjem i posljednjih se nekoliko godina nalazi na listi poželjnih zanimanja u Republici Hrvatskoj. Prema podatcima Središnjega prijavnog ureda za upise studenata na studije u Republici Hrvatskoj, posljednjih dviju godina na jedno se studentsko mjesto na redovnom studiju sestrinstva Zdravstvenog veleučilišta prijavljuje 12 do 13 kandidata. Studiji sestrinstva postaju sve atraktivniji i za učenike koji su završili nemedicinske srednje škole poput gimnazija, srednjih strukovnih i ekonomskih škola. Prilikom odabira profesije budući studenti dolaze s formiranim stavovima o sestrinstvu i cijenjenosti profesije, koji su tijekom studija podložni promjenama. Nerijetko studenti dolaze s idealističnom i nerealnom percepcijom sestrinske profesije. Tijekom edukacije student usvaja profesionalni identitet i socijalizira se u sestrinskoj profesiji. Profesionalna socijalizacija kompleksan je proces tijekom kojeg osoba usvaja znanja, vještine, stavove i osjećaj profesionalne pripadnosti koji su karakteristični za člana profesije. Na stvaranje profesionalnog identiteta utječu brojni čimbenici, poput kurikuluma, edukatora, kliničkih asistenata, medicinskih sestara na odjelima, obitelji, prijatelja, okoline u bolničkim i izvanbolničkim ustanovama ${ }^{1}$. Iznimno je važno tijekom edukacije primjereno utjecati na razvoj profesionalnog identiteta kako bi se formirali profesionalci koji će se uklopiti u radnu okolinu i primjereno obavljati odabranu profesiju.

Kao razlozi odabira sestrinske profesije u literaturi se navode želja za ljudskim kontaktom, mogućnost pomaganja drugima, osjećaj da rade nešto korisno i sigurnost radnog mjesta ${ }^{2-5}$. Jedan je od razloga za odabir sestrinske profesije i prethodni kontakt s medicinskim sestrama koje su njegovale nekog od članova njihove obitelji, odnosno poznavanje medicinskih sestara (medicinska je sestra član obitelji ili prijatelj obitelji). Značajan je razlog odabira profesije i mobilnost unutar profesije, mogućnost putovanja i rada izvan matične zemlje ${ }^{4}$.

I danas, u 21. stoljeću, medicinske se sestre susreću s problemima povezanima s prezentacijom sestrinstva u javnosti. Nerijetko je u medijima dominantnija stereo- tipna prezentacija medicinske sestre u odnosu na realnu. Stereotipije se značajnije naglašavaju u američkoj sestrinskoj literaturi, no procesi globalizacije čine ih dostupnima svagdje. Dominiraju feminizirani stereotipi, medicinske se sestre prikazuju kao žene, a naglasak se stavlja na tradicionalne ženske uloge (majka, supruga, ljubavnica). Kao najčešći prikazi dominiraju medicinska sestra anđeo, oštrokondža, nestašna (seksi) medicinska sestra i pomoćnica liječnika ${ }^{6-8}$. Nerijetko se uz medicinske sestre vezuje manjak znanja i inteligencije u odnosu na liječnike, kao i poslušnost liječnicima ${ }^{9,}{ }^{10}$. Kao najčešće stereotipije na kanalu YouTube izdvajaju se medicinska sestra kao „vješti znalac i činilac", seksualna igračka i budalasta, nekompetentna osoba ${ }^{11}$.

Upravo zbog utjecaja medija i stvaranja stereotipnih prikaza medicinskih sestara, a u svrhu dobivanja realne slike o sestrinskoj profesiji, proveden je niz istraživanja među medicinskim sestrama i općom populacijom kako bi se utvrdilo mišljenje medicinskih sestara i opće populacije o sestrinstvu. Cohen ${ }^{12}$ navodi da medicinske sestre u Sjedinjenim Američkim Državama smatraju da na stvaranje slike o sestrinstvu najveći utjecaj ima način kako se medicinske sestre prezentiraju pacijentima i njihovim obiteljima, koliko su vješte u obavljanju svojeg posla te mišljenje pacijenta/obitelji je li medicinskim sestrama stalo do pacijenta tijekom skrbi. Manninen ${ }^{13}$ navodi da opća populacija u Finskoj medicinske sestre smatra dobro educiranima, a sestrinstvo cijenjenom profesijom. Donelan i suradnici ${ }^{14}$ navode da društvo u Sjedinjenim Američkim Državama također cijeni medicinske sestre.

Istraživanje provedeno u Hrvatskoj 2011. godine na 3005 ispitanika uključivalo je pitanja o zadovoljstvu građana radom javnih službi te je procjenjivana i kvaliteta javnih usluga na skali od 1 do 4 . Najbolje ocijenjeni javni radnici bile su medicinske sestre s ocjenom 3,24, a liječnici su ocjenjeni ocjenom 3,18 $18^{15}$.

Istraživanje provedeno na studentima treće godine studija sestrinstva u Hrvatskoj ukazuje na to da studenti smatraju da je sestrinstvo potplaćena profesija, kao i da sestre nisu dovoljno cijenjene ${ }^{16}$. Takvi su rezultati dobivani i tijekom istraživanja na studentima završnih godina studija u Kanadi te Sjedinjenim Američkim Državama ${ }^{17,18}$.

Po završetku studija, na početku karijere, studenti imaju uglavnom pozitivno mišljenje o sestrinstvu ${ }^{19}$ te smatraju da su medicinske sestre odgovorne za pad mišljenja o sestrinstvu. Naime smatraju da, ako sestre ne cijene znanje i vještine drugih medicinskih sestara, malo je vjerojatno da će ih cijeniti drugi zdravstveni profesionalci. 
Na početku studija kao osnovne zadatke koje medicinske sestre obavljaju studenti navode medicinskotehničke zadatke i njegovanje, dok na kraju studija navode i aktivnosti povezane s profesionalizacijom sestrinstva zasnovanom na istraživanjima, promocijom zdravlja i profesionalnom skrbi za pacijenta ${ }^{13,20,21}$.

Ova kvalitativna ${ }^{22}$ studija donosi informacije o tome kako studenti studija sestrinstva percipiraju segmente sestrinstva na početku studija te koliko se njihova percepcija razlikuje od percepcije zaposlenih medicinskih sestara. Studija donosi podatke koji mogu utjecati na razvoj profesionalnog identiteta.

\section{Metode}

Cilj istraživanja bio je utvrditi mišljenja studenata studija sestrinstva i zaposlenih medicinskih sestara o zadaćama i ulogama medicinskih sestara, vrijednostima koje se vežu uz sestrinstvo i o prepoznatljivosti medicinskih sestara te mišljenja ispitanika o tome što pacijenti, liječnici i društvo misle o medicinskim sestrama. Također smo željeli utvrditi razlike u mišljenjima između dvije skupine ispitanika (studenata i medicinskih sestara).

$\mathrm{U}$ istraživanju je sudjelovalo 38 studenata prve godine studija sestrinstva Zdravstvenog veleučilišta te 12 zaposlenih medicinskih sestara. Zbog različitosti studenata koji studiraju na studiju sestrinstva, u istraživanje su uključeni studenti s prethodno završenim srednjoškolskim obrazovanjem za medicinske sestre (21 ispitanik) i 17 studenata koji su završili druge srednje škole. Pri tome su u istraživanje uključeni ispitanici sa završenim gimnazijskim obrazovanjem (12 ispitanika) te pet ispitanika sa završenim ostalim srednjim školama (ekonomska, strukovna). Dob ispitanika kretala se u rasponu 18 do 30 godina (prosječna je dob 19,6) i sudjelovala su tri studenta muškog spola.

Zaposlene medicinske sestre rade na klinici za kirurgiju zagrebačke kliničke bolnice. Prosječna dob zaposlenih medicinskih sestara bila je 39,6 godina (raspon od 22 do 60 godina) te su sudjelovala dva ispitanika muškog spola.

U svrhu istraživanja primijenjen je upitnik koji je obuhvaćao demografske podatke (dob, spol), podatke o prethodno završenom obrazovanju te sedam pitanja otvorenog tipa: „Što medicinske sestre rade?“, „Koje su njihove uloge i zadaće?", „Po čemu su medicinske sestre prepoznatljive?“, „Koje se vrijednosti vežu uz medicinske sestre i sestrinstvo?“, „Što je važno medicinskim sestrama?“, „Što pacijenti misle o medicinskim sestrama?“, „Što liječnici misle o medicinskim sestrama?" te „Što društvo misli o medicinskim sestrama?“.

Nakon pristanka na sudjelovanje u istraživanju studentima i medicinskim sestrama ispitivači su podijelili upitnik te su ispitanici anonimno i individualno ispunjavali upitnik, vrijeme odgovaranja na postavljena pitanja nije bilo ograničeno, kao ni duljina odgovora. Svi su odgovori obrađeni, neovisno o duljini.

Glavni je istraživač analizirao sve odgovore ispitanika te ih kategorizirao ovisno o postavljenim pitanjima. Odgovori na pitanja „Što pacijenti misle o medicinskim sestrama?“, „Što liječnici misle o medicinskim sestrama?" te "Što društvo misli o medicinskim sestrama?" kategorizirani su u kategorije: pozitivno, negativno te podijeljena mišljenja. Ostali su istraživači pregledali kategorizacije odgovora te je učinjena završna kategorizacija odgovora.

\section{Rezultati i rasprava}

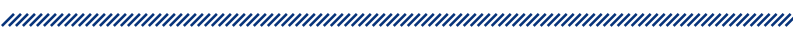

Na pitanja „Što medicinske sestre rade?“ i „Koje su njihove uloge i zadaće?" zaposlene medicinske sestre odgovaraju jednostavno - zdravstvena njega, zadovoljavanje osnovnih ljudskih potreba; te navode najčešće i po njihovoj percepciji najznačajnije intervencije koje obavljaju:

- zadovoljavanje osnovnih ljudskih potreba, edukacija, promicanje zdravlja, čuvanje dostojanstva (medicinska sestra-MS3)

- zbrinjavanje pacijenta od prijama do otpusta, podjela terapije, mjerenje vitalnih znakova, informiranje liječnika o promjenama stanja pacijenta (MS4)

- zdravstvena njega, podjela terapije, vađenje krvi, pratnja bolesnika na dijagnostičke pretrage (MS11).

Studenti u odnosu na zaposlene medicinske sestre opsežnije odgovaraju na pitanje što medicinske sestre rade. Dominiraju odgovori: brinu se za pacijente i zadovoljavanje osnovnih ljudskih potreba. Studenti navo- 
de i kako bi se sestre pritom trebale ponašati: svakom bolesniku pridaju jednaku važnost (student - S21), treba biti požrtvovna u svom radu, empatična, mora surađivati s ostalim članovima tima (S13). Dio studenata nabraja medicinskotehničke zadatke poput kupanja, slaganja kreveta, podjele terapije i asistiranja liječnicima.

Budući da je istraživanje provedeno tijekom drugog semestra studija i do tada su studenti odslušali veći dio nastave, uočljiv je utjecaj teorijskog dijela edukacije u odgovorima studenata. Studenti navode definicije i sadržaje koji su prezentirani tijekom predavanja i seminara:

- Pomoć pojedincu, bolesnom ili zdravom, u obavljanju aktivnosti koje pridonose zdravlju, oporavku ili mirnoj smrti, a koje bi obavljao samostalno kad bi za to imao potrebnu snagu, volju ili znanje. (S14)

- Medicinske sestre provode postupke i intervencije koji pridonose poboljšanju zdravlja pacijenta ili mirnoj smrti. Njihova je uloga da se brinu za pacijenta i njegovu obitelj, da sudjeluju u dijagnostičkim postupcima te provode zdravstvenu njegu $i$ intervencije koje se odnose na zadovoljavanje osnovnih ljudskih potreba kod pacijenta. (S12)

- Pomoć bolesnom i zdravom pojedincu u sprječavanju bolesti, liječenju, oporavku ili mirnoj smrti. Orijentirane su prema pacijentima i njihovim obiteljima, pružaju fizičku i psihičku pomoć. (S3)

- Medicinske se sestre brinu o pacijentima, njihovim osnovnim ljudskim potrebama, promiču i održavaju zdravlje, planiraju, provode i vrednuju zdravstvenu njegu. (S17)

Kod studenata su uočljivi opsežniji i obuhvatniji odgovori, što je vjerojatno posljedica svladavanja sadržaja na teorijskom dijelu nastave. Studenti navode i vrlo složene intervencije poput promicanja zdravlja, sprječavanja bolesti te provođenja i vrednovanja zdravstvene njege, no pitanje je koliko su navedene intervencije njima poznate i koliko razumiju što obuhvaćaju.

Dvije trećine zaposlenih medicinskih sestara navode da su prepoznatljive po uniformi, uz uniformu navode nasmijano lice, težak rad i komunikativnost.

Većina studenta navodi da su sestre prepoznatljive po uniformi, uz uniformu studenti koji su završili srednju medicinsku školu navode humanost i brižnost. Studenti koji su prije upisa na studij završili gimnaziju i druge škole navode i male plaće te težak i zahtjevan posao.

Kao vrijednosti koje se vežu uz sestrinstvo zaposlene medicinske sestre najčešće navode brižnost, huma- nost, požrtvovnost i stručnost. U navodima dominiraju vrijednosti koje se odnose na karakterne osobine (brižnost, strpljivost, susretljivost).

Studenti studija sestrinstva koji su prethodno završili srednju medicinsku školu najčešće navode humanost, brižnost, dobrotu, požrtvovnost i empatiju. Studenti koji su završili druge srednje škole kao vrijednosti izdvajaju humanost, dobrotu, komunikativnost, empatiju, ljubaznost i požrtvovnost. Dio studenata koji su završili druge srednje škole kao vrijednost navode i hrabrost. Studenti uz vrijednosti koje se odnose na karakterne osobine češće navode i vrijednosti koje se vezuju uz obavljanje posla (spretnost, radišnost, odgovornost, strpljivost).

Studenti navode više pojmova povezanih s vrijednostima u odnosu na zaposlene medicinske sestre $(55: 21)$, no najčešći su pojmovi koji navode sestre i studenti jednaki: brižnost i humanost.

Na pitanje „Što je važno medicinskim sestrama?“ zaposlene medicinske sestre najčešće navode uvjete rada (sredstva za rad, dovoljan broj osoblja), potom status (da su cijenjene, adekvatno plaćene) te stanje pacijenta (zadovoljan pacijent, zdravlje pacijenta).

Studenti sestrinstva u najvećoj mjeri navode zadovoljstvo pacijenta, potom profesionalni status (cijenjena profesija) te znanje i vještine (posjedovanje znanja $i$ vještina kako bi mogla kvalitetno provoditi zdravstvenu njegu i edukaciju te stvoriti odnos povjerenja (S1)), timski rad i profesionalnost.

U dijela studenta prisutan je idealističan pogled na profesiju, što je svojstveno studentima. Najvažnije je pomoći pacijentima koliko je to u njihovoj moći i vidjeti osmjeh na pacijentovu licu. (S14)

Zaposlene medicinske sestre ističu uvjete rada, što se može povezati s teškom ekonomskom situacijom i nezapošljavanjem novog osoblja, dok studenti na prvom mjestu navode pacijente, ali navode važnost znanja i vještina jer prepoznaju da im nedostaju upravo znanje i vještine sestrinske prakse.

Profesionalci na osnovi vlastitih doživljaja, ali i stava javnosti, pojedinaca i medija stvaraju sliku o tome kako in drugi doživljavaju. Medicinske sestre u neprestanoj su interakciji s pacijentima i liječnicima te je stoga iznimno značajno znati što one misle o tome kako ih doživljavaju pacijenti, liječnici i društvo.

Većina medicinskih sestara (8) navodi da pacijenti imaju pozitivno mišljenje o medicinskim sestrama, da misle 
da sestre mnogo rade, slabo su plaćene te da su savjesne, brižne, stručne i vrijedne. Samo je jedna ispitanica navela da pacijenti imaju negativno mišljenje o medicinskim sestrama, a jedna navodi: Mišljenja su različita, ovise o obrazovanju, prijašnjem iskustvu, očekivanjima pacijenata. (MS5)

Većina studenata (18) navodi da pacijenti imaju podijeljena mišljena o medicinskim sestrama te da ona ovise o iskustvu pacijenta.

- Ovisi kako koji pacijent, to uvelike ovisi o ponašanju medicinske sestre. Ako je sestra profesionalna, pacijent će naći riječi hvale za nju. Ako je neprofesionalna, pacijent će o njoj imati loše mišljenje i to će i pokazati svojom neverbalnom i verbalnom komunikacijom. (S13)

- Ovisi o iskustvima pacijenata, neki imaju pozitivno mišljenje o sestrama, ali ima i onih koji zbog loših iskustava nemaju dobro mišljenje o njima. (S16)

Šesnaestero je studenata navelo da pacijenti imaju pozitivna mišljenja o medicinskim sestrama, dio studenata navodi idealistična mišljenja: Sve najbolje, misle da su one njihovi anđeli (S17); Uvijek tu za njih, anđeo čuvar (S10); Smatraju ih svojim anđelima čuvarima. (S3). Za razliku od zaposlenih medicinskih sestara, nijedan student ne misli da pacijenti imaju isključivo negativno mišljenje o sestrama, no studenti navode stereotipne prikaze medicinskih sestara.

Price $^{23}$ navodi da studenti formiraju mišljenja na temelju interakcija sa sestrama i iskustva na vježbama te da je kod dijela studenta prisutan idealističan doživljaj sestrinstva koji može uzrokovati poteškoće i nezadovoljstvo prilikom boljeg upoznavanja profesije i zapošljavanja. Prilikom zapošljavanja diplomirani student suočava se s nerazmjerom idealne slike o profesiji koju posjeduje i realnosti. Kod studenata s nerealnom slikom profesije prisutno je češće odustajanje od nastavka i završetka studija ${ }^{24}$.

Studenti svoja mišljenja formiraju na osnovi svojih dosadašnjih iskustava s pacijentima, a dio studenata ima relativno malo iskustva, s obzirom na to da je riječ o studentima prve godine studija, a neki od njih prethodno nisu završili srednju školu za medicinske sestre. Dio ispitanika navodi i stereotipne prikaze medicinskih sestara gdje je vidljiv utjecaj teorijskog dijela nastave i medija na formiranje mišljenja.

Medicinske sestre u manjoj mjeri misle da liječnici o sestrama misle pozitivno, većina sestara (6) smatra da liječnici imaju podvojena mišljenja i većina je navela da liječnici smatraju da sestre moraju stalno biti dostupne liječnicima i slušati ih. Zaposlene medicinske sestre mišljenja stječu na temelju svakodnevnih iskustava na radnom mjestu. Budući da je istraživanje provedeno na jednoj klinici (nekoliko odjela), mišljenja mogu biti uvjetovana međuljudskim odnosima na tim odjelima, odnosno njihovim dosadašnjim iskustvima, i nije ih moguće generalizirati.

Kod studenata dominiraju pozitivna (16) i podijeljena (13) mišljenja, a dio studenata (8) navodi negativna mišljenja liječnika o medicinskim sestrama. Studenti prve godine studija imaju malo kliničkih bolničkih iskustava i iskustva u izravnom radu s liječnicima te se može pretpostaviti da je takvo mišljenje posljedica stereotipija s kojima su se susreli u literaturi i javnim medijima. Studenti formiraju mišljenja i promatrajući odnos medicinska sestra - liječnik tijekom kliničke prakse.

- Na zadnjoj praksi vidjela sam odličnu kompatibilnost među doktorima, sestrama i ostalog osoblja, što me divno iznenadilo. (S15)

No ipak većina studenata, više od dvije trećine, za razliku od zaposlenih medicinskih sestara, smatra da liječnici imaju pozitivna i podijeljena mišljenja. Studenti u manjoj mjeri navode da liječnici smatraju medicinske sestre podređenima. Navedena su mišljenja iznimno značajna za budući timski rad i suradnju s liječnicima.

Budući da zaposlene medicinske sestre imaju značajan utjecaj na formiranje stavova prema profesiji ${ }^{23,25}$, vrlo je važno odabrati pozitivnu okolinu za poučavanje studenata, jer dolazak u sredinu u kojoj dominiraju negativna mišljenja može potaknuti razvoj i učvršćivanje negativnih mišljenja kod studenata.

Zaposlene medicinske sestre smatraju da društvo ima negativna mišljenja (8) o medicinskim sestrama: Da ništa ne rade, šeću u uniformi (MS4); Da šetamo hodnicima, da smo previše plaćene (MS9); Ništa ne rade, samo piju kavu.(MS11). Samo je jedna ispitanica navela: Društvo ima visoko mišljenje o sestrama, smatraju da su one žrtve svog posla, da su podcijenjene, da rade u lošim uvjetima (MS2). Pet od 12 ispitanica navelo je da društvo smatra da su medicinske sestre slabo odnosno premalo plaćene.

Gotovo trećina ispitanih studenata (11) navodi da društvo ima stereotipna mišljenja o medicinskim sestrama (oštrokondža, seksualni objekt, anđeo, pomoćnica liječnika), a nijedna zaposlena medicinska sestra nije navela navedene stereotipije. Mišljenja studenata na- 
stala su pod utjecajem edukacije. Budući da se tijekom predavanja prezentiraju navedene stereotipije, studentima su poznatije i lakše im ih je navesti. Jednaki broj studenta $(7+7)$ navodi da društvo ima pozitivno ili negativno mišljenje o medicinskim sestrama. Preostali dio studenata (12) ima podijeljena mišljenja: Društvo misli kako se medicinske sestre bave jednim od najhumanijih zanimanja. Nažalost, postoje i oni koji imaju stereotipe o medicinskim sestrama, društvo zna biti povedeno medijima. (S14).

Razdoblje bolesti posebno je osjetljivo razdoblje u kojem se lako mogu stvarati i negativni stavovi prema profesiji, posebno ako je pacijent očekivao (opravdano ili neopravdano) znatno veću podršku i pomoć medicinskih sestara. Također i ishod liječenja može utjecati na stvaranje mišljenja o sestrinstvu kao profesiji te ne čudi da dio populacije ima i negativan stav o sestrinstvu i da to studenti prepoznaju, kao ni da prepoznaju postojanje podijeljenih mišljenja.

Studenti smatraju da pacijenti, liječnici i društvo imaju pozitivnija mišljenja o medicinskim sestrama nego što to smatraju zaposlene medicinske sestre. $U$ ovom istraživanju medicinske sestre u većoj mjeri smatraju da liječnici i društvo imaju podijeljena odnosno negativna mišljenja o medicinskim sestrama, no svakako treba uzeti u obzir da je riječ o malom broju ispitanika i da bi trebalo provesti istraživanja na većem broju ispitanika koji dolaze iz različitih radnih sredina.

\section{Zaključak}

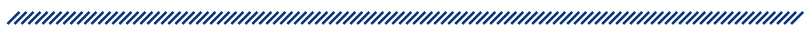

Sigurnost radnog mjesta čini sestrinstvo poželjnim zanimanjem, u proces obrazovanja studenti ulaze s različitim predznanjima povezanima s osobitostima profesije, poslovima i zadatcima koje bi trebali obavljati po završetku obrazovanja. Tijekom obrazovanja razvija se profesionalni identitet i u odgovorima studenta uočljiv je utjecaj edukativnih sadržaja, posebice u odgovorima na pitanja što medicinske sestre rade te pri navođenju stereotipija o sestrinstvu. U manjeg broja studenta prisutna su idealistična razmišljanja i nema značajnijih razlika u odgovorima između studenta koji su prethodno završili srednju školu za medicinske sestre u odnosu na studente koji su završili druge srednje škole. Bilo bi zanimljivo među studentima provesti jednako istraživanje na početku edukacije, prije svladavanja sadržaja povezanih sa sestrinstvom.

Zaposlene medicinske sestre i studenti slažu se u tome da pacijenti uglavnom imaju pozitivna i podijeljena mišljenja o medicinskim sestrama. Uočena je razlika u odgovorima zaposlenih medicinskih sestara i studenta s obzirom na njihova mišljenja o tome što društvo i liječnici misle o medicinskim sestrama. Studenti, za razliku od zaposlenih medicinskih sestara, navode da smatraju da društvo i liječnici imaju pozitivna mišljenja o medicinskim sestrama.

Rezultati istraživanja ukazuju na to da na razvoj profesionalnog identiteta i percepcije o sestrinstvu značajan utjecaj imaju mediji, okolina ali i edukacija. Mišljenja studenata sestrinstva u značajnoj su mjeri usklađena s mišljenjima zaposlenih medicinskih sestara, što može ukazivati na lakše uklapanje na radno mjesto po završetku studija. No s obzirom na to da edukacija i edukativna sredina imaju značajan utjecaj na razvoj profesionalnog identiteta, važno je odabirati kliničke edukacijske sredine koje će omogućavati pozitivan profesionalni razvoj.

Budući da je ovo kvalitativno istraživanje provedeno na maloj skupini ispitanika, samo u jednoj obrazovnoj i jednoj kliničkoj instituciji, potreban je oprez prilikom generalizacije rezultata. Kako bi se dobili vjerodostojniji podatci, potrebno je upitnik prilagoditi za kvantitativnu analizu i primijeniti ga na većem broju ispitanika, u više obrazovnih i kliničkih sredina. 


\section{Literatura}

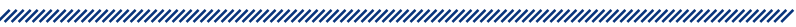

1. Safadi RR, Saleh MYN, Nassar OS, Amre HM, Froelicher ES. Nursing students' perceptions of nursing: a descriptive study of four cohorts. International Council of Nurses. International Nursing Review. 2011;58(4):420-7.

2. Boughn S. Why women and men choose nursing. Nursing and health care perspectives. 2001;22(1):14-19.

3. Bolan C, Grainger P. Students in the BN program - Do their perceptions change? Nurse Education Today. 2009;29:775-779.

4. Mooney M, Glacken M, O’Brien F. Choosing nursing as a career: a qualitative study. Nurse Education Today. 2008;28:358-392.

5. Hemsley-Brown J, Foskett NH. Career desirability: young people's perception of nursing as a career. Journal of Advanced Nursing. 1990;29(6):1342-1350.

6. Cunningham A. Nursing stereotypes. Nursing Standard. 1999;45:46-47.

7. Kalisch BJ, Begeney S, Neuman S. The image of the nurse on the Internet. Nursing outlook. 2007;55:182-188.

8. Bridges JM. Literature review on the images of the nurses and nursing in the media. Journal of Advanced Nursing. 1990;15:850-854

9. Takase M, Maude P, Manias E. Imapct of the perceived public image of nursing on nurses' work behavior. Journal of Advanced Nursing Practice. 2006; 53 (3):333-343.

10. Nielson GR, Lauder W. What do high academic achieving school pupils really think about career in nursing: Analysis of the narrative from paradigmatic case interviews. Nurse Education Today. 2008;28:680-690.

11. Kelly J, Fealy GM, Watson R. The image of you: constructing nursing identities in YouTube. Journal of Advanced Nursing. 2012;68(8):1804-1813.

12. Cohen S. Reflections on the image of nursing [Internet]. Strategies for nurse managers.com. Dostupno na: www. hcpro.com (pristupljeno 10.08.2013.)

13. Manninen E. Changes in nursing students' perceptions of nursing as they progress through their education. Journal of Advanced Nursing. 1998;27:390-398.

14. Donelan K, Buerhaus P, DesRoches C, Dittus R, Dutwin $D$. Public perceptions of nursing careers: the influence of the media and nursing shortages. Nursing economics. 2008;26(3):143-165.

15. Građani Hrvatske: Medicinske sestre najbolji javni službenici [Internet]. Dostupno na: http://nurse.hr/novosti/novosti_sestrinstvo/medicinske-sestre-najbolje. html (Pristupljeno 13.05.2011.)

16. Čukljek S, Karačić J, Ilić B. Stavovi studenata 3. godine studija sestrinstva o sestrinstvu u Hrvatskoj danas. U: Zbornik radova konferencije medicinskih sestara "Hrvatsko sestrinstvo ususret Europskoj uniji“; 24-26.ožujka 2011; Opatija, Hrvatska. Zagreb: Zdravstveno veleučilište; 2011. 169-176.
17. Buerhaus P, Donelan K, Norman L, Dittus R. Nursing students' perceptions of a career in nursing and impact of a national campaign designed to attract people into the nursing profession. Journal of Professional Nursing. 2005;21(2):75-83.

18. Grainger P, Bolan C. Perceptions of nursing as a career choice of students in the Baccalaureate nursing program. Nurse Education Today. 2006;26:38-44.

19. Emeghebo L. The image of nursing as perceived by nurses. Nurse Education Today. 2012;32(6):e49-e53.

20. Granum V. Nursing students perceptions of nursing as a subject and a function. Journal of Nursing Education. 2004;43:297-304.

21. Bolan C, Grainger P. Students in the BN program - Do their perceptions change? Nurse Education Today. 2009;29:775779.

22. Vuletić, S. Kern J. Osnove metodologije javnozdravstvenih istraživanja. Zagreb: Medicinski fakultet Sveučilišta u Zagrebu, Škola narodnog zdravlja Andrija Štampar; 2011.

23. Price SL. Becoming a nurse: a meta study of early professional socialization and career choice in nursing. Journal of Advanced Nursing. 2009;65(1):11-19.

24. Cowin LS, Johnson M. Many paths lead to nursing: factors influencing students' perceptions of nursing. International Nursing Review. 2011;58:413-419.

25. Karaoz S. Change in nursing student' perceptions of nursing during their education: the role of the Introduction to Nursing course in this change. Nurse Education Today. 2004;24:128-135. 


\section{DIFFERENCES IN THE PERCEPTION OF THE NURSING PROFESSION BETWEEN NURSING STUDENTS AND EMPLOYED NURSES}

1 Snježana Čukljek

1 Martina Smrekar

1 Sanja Ledinski Fičko

2 Vesna Konjevoda

1 University of Applied Health Sciences

2 University Hospital Sveti Duh

\section{Abstract

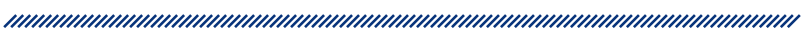

In recent years, due to job security, nursing has been among the desirable professions in Croatia. While choosing their profession, prospective students enter higher education with formed attitudes towards nursing and the esteem of the profession, which can change during the course of their studies.

The aim of this qualitative study was to identify the opinions of nursing students and employed nurses about the tasks and roles of nurses, nursing values, recognizability of nurses, and what patients, doctors and society think about nurses.

Employed nurses and nursing students state that the tasks and roles of nurses are caring for the patients and satisfying basic human needs. Both groups of respondents point out that nurses are recognizable by their uniform, and among nursing values they most often emphasize caring and humaneness. Working conditions are the most important for employed nurses, while nursing students first mention caring for the patient and the importance of knowledge and skills. Both the employed nurses and nursing students agree that patients mainly have either positive or divided opinions about nurses. There was a difference in the answers between employed nurses and nursing students related to their opinion on what the society and doctors think about nurses. Students state, contrary to employed nurses, that the society and doctors have a more positive opinion about nurses. A certain number of students state that the society has stereotyped opinions about nurses.

Research results indicate that the media, society and education have a significant impact on the development of professional identity and perception of nursing. Students' opinions substantially match the opinions of employed nurses which may indicate their easier integration in the workplace after graduation.

Keywords: nursing, perception, professional identity 